\title{
Factors of importance for maintaining work as perceived by men with arthritis
}

\author{
Johannes Hjalmarsson Österholm, Mathilda Björk and Carita Håkansson
}

\section{Linköping University Post Print}

\section{Tweet}

N.B.: When citing this work, cite the original article.

Original Publication:

Johannes Hjalmarsson Österholm, Mathilda Björk and Carita Håkansson, Factors of importance for maintaining work as perceived by men with arthritis, 2013, Work: A journal of Prevention, Assesment and rehabilitation, (45), 4, 439-448.

http://dx.doi.org/10.3233/WOR-121542

Copyright: IOS Press

http://www.iospress.nl/

Postprint available at: Linköping University Electronic Press

http://urn.kb.se/resolve?urn=urn:nbn:se:liu:diva-91246 


\section{Factors of importance for maintaining work as perceived by}

men with arthritis.

Authors: Johannes Hjalmarsson Österholm, Doctoral student, MSc, Reg OT.

Linköping University, Institute of Medical and Health Science, Division of Health and Society, Center for dementia research [CEDER].

Mathilda Björk, PhD, Reg OT. Jönköping University, School of Health Sciences, Department of Rehabilitation.

Carita Håkansson, PhD, Reg OT. Lund University, Division of Occupational and Environmental Medicine.

Address for correspondence:

Johannes Hjalmarsson Österholm.

Linköping University

Department of Medical and Health Sciences (IMH)

Division of Health and Society

SE-581 83 Linköping

SWEDEN

johannes.h.osterholm@liu.se 


\begin{abstract}
Objective: Employment rates are significantly lower among individuals with arthritis compared to a general population. There is, however, limited research about how men with arthritis perceive their ability to maintain working. The aim of this study was thus to explore their perception of this. Participants: Nine employed men with arthritis were purposively sampled. Methods: Interviews were performed and were informed by the central concepts of the Model of Human Occupation. The Empirical Phenomenological Psychological method was modified and used to analyze and interpret collected data. Results: The findings showed that men with arthritis perceived a desire to work, adjusted their activity pattern, were aware of their own capabilities, had good work conditions, had environmental support and used effective medication to maintain their ability to work. Conclusions: The findings suggest that health care professionals can help men with arthritis to find strategies and a balance between recreation and work. Ultimately, this knowledge could guide health care professionals to target men needing interventions to prevent sick leave.

Key words: Ability to work, Empirical Phenomenological Psychological method (EPP), , Rheumatism, Rheumatology, Work ability.
\end{abstract}




\section{Introduction}

Within the first five years after a diagnosis of arthritis 25 to 40 per cent become work disabled (1-4) and the employment rates are significantly lower among individuals with arthritis compared to a general population (5). As well as causing pain, low mood, fatigue and impairments (6), arthritis is an expensive issue for society. Individuals with arthritis have themselves identified work as a prioritized outcome of treatment $(7,8)$. During the last decade new biological medications have revolutionized the treatment for many individuals with arthritis (9), reducing the disease activity and symptoms in a positive way, but also causing major direct costs since the new medications are very expensive (10). Even though the effect is good, some individuals still report disability like pain, fatigue (11) and work disability (12). This indicates that even though biological medicines generate a positive remission of the disease, disability such as work disability can still be present and needs to be evaluated.

Work has a significant impact on quality of life and the ability to contribute to society (13). The individuals' volition to engage in occupations that are meaningful for them but also meaningful in a socio-cultural context, affects their ability to maintain working (14). Lifestyle changes and a re-evaluation of self-perception begin after a diagnosis of arthritis. This often includes a reduction of social and leisure activities but also home life has to be altered in order to experience a balance between work and relaxing activities (4), which was important in maintaining an ability to work for individuals with arthritis (15). The individual has a need to challenge and master the disease but also to re-organize their whole life situation in order to adapt to the disease and make the best of the situation (16). Other factors of importance in order to be able to continue working after a diagnosis of arthritis is a flexible (4) and modified (17) environment at work with a high level of accessibility (18), support from the social environment (4), and low physical demands (19). Impairments such as hand 
dysfunction and pain (20-22), and different personal factors such as high age, emotional problems, low education levels and female gender had a negative effect on ability to work among individuals with arthritis (19).

There is no consensus whether there is a difference in sick-leave between men and women with arthritis $(17,20,23)$. Nevertheless, their experiences of their work situation are different. According Kaptein et al., men report more negative work experiences compared to women (17), while it is more socially accepted for women to stop working and engage in other social and cultural roles (14). Men tend to struggle more than women to meet social and cultural values and are more likely to prioritize paid work over their own health (24). Men experience less pain (25) and physical structural limitations than women, while the latter used technical devices more frequently (26) and had more adjustments to their workplaces than men (4). Previous research about individuals with arthritis and their ability to work has mainly had a quantitative design, focusing on what affects work and facilitates the ability to work for women. A need to explore how men with arthritis maintain their ability to work was identified.

The aim of this study was to explore how men with arthritis perceive their ability to maintain working.

\section{Material and methods}

\subsection{Participants}

The executives at three rheumatology clinics in southern Sweden were contacted and informed about the aim of this study and gave their consent. An information letter was distributed to individuals who fulfilled the inclusion criteria via occupational therapists at these rheumatology clinics. Those who were interested in taking part in this study returned an informed consent by mail to the first author. The informants were then contacted by telephone by the first author to make an appointment for an interview about their perceptions 
of maintaining their ability to work. Inclusion criteria were men between 25 and 65 years old with arthritis, who were employed, able to speak fluent Swedish and treated at one of the rheumatology clinics between 2006 and 2011. The informants were purposively sampled to this study in February 2011.

A total of fourteen individuals were contacted. One individual declined to participate, three were not available by telephone and another did not meet the inclusion criterion of "being employed". A pilot interview was conducted with the latter. Nine individuals thus agreed to participate. The age span for the informants was 31 to 62 years with a mean age of 48 years. Demographic data are presented in Table 1. Ethical approval for this research was obtained through the Linköping Regional Ethical Review Board (Dnr: M86-09).

Table I in here

\subsection{Data collection}

In-depth, informal and interactive interviews were conducted and inquiry areas were constructed from the central concepts of the Model of Human Occupation (MOHO): volition, habituation, performance capacity and environment (27). One pilot interview was conducted which made it possible to test the interview questions and rephrase those which appeared to be difficult for the respondent to comprehend.

It was optional for each respondent to choose where to conduct the interview. Five interviews were conducted at the rheumatic clinics and two interviews at the informants' workplaces. In two situations it was impossible to arrange a physical meeting and interviews were thus conducted by telephone. Each interview was taped and transcribed verbatim. 


\subsection{Data analysis}

Data analysis was conducted with a modified (28) form of the Empirical Phenomenological Psychological (EPP) method in five steps. This modification includes a theoretical shift from a psychological perspective to an occupational therapy perspective. The EPP method is a qualitative and interpretive method. Steps one to four in the data analysis were carried out separately for each informant (29). Table 2 gives examples of the analysis process.

1. To gain a good grasp of the content; transcripts were read repeatedly in order to reach a sufficient understanding of them. In this step the author was open to the text and did not impose any theoretical explanation upon it.

2. Transcripts were then searched line by line to organise the text into meaning units.

3. Each meaning unit was transformed into the researcher's language; by using an eidetic induction interpretation was moved from embedded facts relating to the phenomenon into its implicit and explicit meaning.

4. The implicit and explicit meaning of each transformed meaning unit was then synthesized into summary formats (situated structures) and themes and sub-themes emerged. Meaning units were omitted and shifted in this step; the researcher was free from the subjects' structure but there had to be interconnectedness between the whole and the parts. Thus it was important to return to and control themes and sub-themes towards the informants' texts.

5. In the final step a general structure were compiled by comparing all situated structures with each other. Revealed themes and sub-themes in the situated structures were integrated in the general structure. Themes and sub-themes were presented in running text without losing essence together with significant quotations from meaning units.

Table 2 in here 
The first author conducted step one to five alone. Peer examination (30) by the third author was included in steps four and five in order to establish validity. Significant quotations were used to strengthen the validity of the results. Validation was examined in relation to horizontal consistency of interpretations in steps four and five, which entails going back to each informant's text and seeing if interpretations were consistent with the meaning revealed in the other informants' text. Interpretations that were not compatible with the rest of the data analysis were rejected (29).

The first author has work experience from other fields than arthritis practice which gave an opportunity to be opened minded to the subjects' experiences when the data analysis was conducted. On the other hand the authors' theoretical knowledge as occupational therapists cannot be ignored when interpreting the results of this study. To minimize this effect reflections have been done during all stages of the data analysis to become aware of mental models (30). Also the horizontal consistency of interpretations (29) was done to make sure that the researchers mental models were not transferred to the results.

\section{Results}

The findings consist of six themes and fifteen sub-themes. These are presented in table 3 . The general structure of themes and sub-themes was compiled by using a majority of the respondents situated structures (29). The themes were (a) desire to work, (b) adjusted activity pattern, (c) awareness of own capabilities, (d) good work conditions, (e) environmental support and (f) use of good medication.

Table 3 in here 


\subsection{Desire to work}

The informants experienced that a meaningful work and a desire to be as everyone else was influential for them in maintaining their ability to work. The informants had a strong desire to be engaged in work. A desire to work was perceived as influencing the informants in maintaining ability to work even if their skills or capacity to work had been reduced. Having a positive attitude towards work and to their arthritis affected their ability to maintain to work and their desire to work also increased the tolerance level for what the informants endured in order to maintain their ability to work.

Meaningful work. Work and the social aspects of work were highly valued and expressed as facilitating for the informants to maintain their ability to work. Those informants who perceived that they had an exciting, stimulating, challenging and interesting work experienced this as a driving force to maintain at work.

Desire to be as everyone else. In order to reduce the feeling of being different or odd because of their arthritis the informants carried out their work despite pain and the risk of having setbacks. When the informants were working they experienced a feeling of being as everyone else: - So I would like to engage in working life as everyone else ... I would like to live as usual ...I used to bite the bullet to be able to continue to work (I). It was of such importance for the informants to be engaged in work that they exceeded themselves and their health to keep working. They perceived a pride in being able to continue to work. Work was expressed as being a large part of their identity: - I am a man and therefore I go to work (VIII). They also perceived an income as a statement that they were a part of society and expressed that their living situation would drastically change if they did not work because of low sick leave compensation. The informants thus felt obliged to continue to work despite their arthritis. 
-Instead of early retirement it was better to continue to work ... early retirement compensation was sixty percent of what I made today. Then I had a hard time imagining how I would be able to keep the house and I started to consider to selling the house (IV)

\subsection{Adjusted activity pattern}

The informants had adjusted leisure activities, engaged in more recreation and had adjusted household activities in order to maintain ability to work.

Adjusted leisure activities. As the disease developed the informants had reduced their leisure activities and prioritized their work to maintain their ability to work. Most informants had in the past been active in physically demanding leisure activities: - When it started to get complicated I quit with my physical leisure activities (IV). This had been adjusted because of their arthritis and nowadays they participated in less demanding leisure activities (walks, socializing with friends or listening to music).

More recreation. Fatigue at and after work has increased as the arthritis progressed. To cope with work and maintain ability to work informants experienced that they needed more recreation. The ways in which they were able to recreate varied in accordance with the individuals' situations. The informants expressed that they took more breaks during working hours while others rested after work or slept more at nights or at weekends: - I take more pauses than my colleagues ... I need to take a rest after each lunch. I do not sleep but I lay down to rest ... when I get home I take a rest for forty-five minutes (III). Sleep was essential for them in order to be able to go to work the next day. It was expressed as being a vicious circle where perceived pain and stiffness increased if there was not a balance between recreation and work: - Sometimes it can be worse if I have some good days when I take it easy ... so sometimes I wonder if it does not get worse when I do nothing (VI)

Adjusted household activities. The informants reduced demanding household activities in order to maintain or increase their ability to work. Sometimes they split up or postponed 
heavy household activities to another day in order to maintain their ability to work: - It is difficult for me to execute heavy tasks. But it has been so all the time since I got rheumatism ... I need to take it easier and things simply take a longer time to do (III) They also adjusted household activities by buying the services of a window cleaner or asking their friends and family members for help: - Then I may tell my wife that she has to do things or I let it be until another day (VIII).

\subsection{Awareness of own capabilities}

The informants perceived that they needed to learn to live with reduced capabilities, adjusted work pace but also adjusted movement patterns in order to maintain their ability to work, they needed to be aware about their own abilities and restrictions. The amount of work was perceived to be the same as before they were diagnosed with arthritis.

Learn to live with reduced capabilities. Self awareness seemed to evolve over time along with the disease. Those who had lived with arthritis for a long time had accepted their disease and learned to live and cope with their restrictions. This made it possible for them to adapt to their situation and find solutions to increase or maintain their ability to work: - In the beginning of the disease there was a change of situation and I wonder what would happen. But then you start to learn how to cope (I). Another informant stressed: - when you have had it as long as I have it is not strange at all. It is a part of daily life (II).

Adjusted work pace. The informants spoke of needing to adjust tasks or effort at work in accordance with how they felt each day in order to maintain the ability to work. They split up work tasks or adjusted the pace of how they executed heavy and difficult work tasks: Earlier I had a much higher pace ... but now when I cannot move as quickly as I want to I have to slow down the pace (III). The informants worked at their own pace and thus everything took longer to perform. 
Adjusted movement pattern. In order to avoid uncontrolled movements the informants perceived that they needed to control and adjust their movement patterns for maintaining their ability to work. The informants perceived that being as they were diagnosed with arthritis their movement patterns had been gentler and slower so as to avoid reckless movements and sudden jerks when they executed their work. The informants also expressed that they had adjusted their ways of walking and standing when working. They walked more slowly and when standing they shifted their weight between both legs: - I am not as reckless any more when I do things ... I think my pattern of movement is calmer than before (IV).

\subsection{Good work conditions}

The fourth theme was good work conditions and includes flexible work conditions and a predictable workday.

Flexible work conditions. Conditions of work were expressed as being a prerequisite for maintaining their ability to work. They expressed that it was possible to continue to execute heavier work tasks (lifting or carrying things) if they had the opportunity to alternate with lighter work tasks (meetings or paperwork): - I got a flexible work. It is not that I am sitting and working for sixteen hours on the run. Sometimes a colleague needs to talk with me or we take a coffee and talk for a while (VIII)

Predictable workday. Ability to work was perceived to be positively influenced by predictable work and when the informants had the opportunity to plan their workday. - You always need to think about what you are doing and plan the next step. How to lift things or when to call for help (VII). Planning was seen as helping them to minimize the risk of stressful situations and unpredicted events which could affect their ability to work negatively: - There are a lot of different things that need to run smoothly. There is little room if there is a problem ... when something goes wrong it becomes difficult to cope $(V)$. 


\subsection{Environmental support}

Environmental support included objects and space at the workplace and the size of the company but also support from colleagues, families, and authorities and health care services.

Objects and space at the workplace. Ability to work was maintained by standard ergonomic adjustments at the workspace to facilitate for all staff members.- I guess my workspace is adjusted but it has been adjusted in the same way as for everyone else (VII). The informants expressed that a good workspace allowed them to have varying sitting positions, to be able to lie down and have the opportunity to walk in their workplace. In order to maintain the ability to work the informants stopped working outdoors because of cold weather and continued to work indoors in a warm temperature: - I stopped working outside after arthritis and have been working indoors recently and I have been feeling very good since then (IV). Objects such as an adjusted computer mouse and orthotic devices were used in the workplace for maintaining their ability to work.

The size of the company. To work in a large company provides a sense of security. - It is a big employer. If I do not have the ability to execute my work then they can test me at another workplace. A workplace which is more suitable for me (VI). Meanwhile those working in a small company had the knowledge that if they could not cope with their work demands they could be discharged: - It is a little company ... either you work as everyone else does or you have to stay at home (IX). This was expressed as an overhanging and stressful demand.

Support from colleagues. Colleagues were perceived to be facilitators for the informants to maintain ability to work. The informants had informed their colleagues about their arthritis but not the degree to which the disease affected them or their ability to work. The informants did not want to be seen as an exception by their colleagues: - They know that I have some sort of illness but they do not know how serious it is and that isn't anything they need to know. (VIII). Colleagues were perceived to be a social safety net, and if it became difficult to 
perform at work they knew that their colleagues would support and help them: - My colleagues understand me completely. They cover up for me if I need to be free from work or have to go away for a minute ... we get the job done together (VII).

Support from families. Informants perceived a great support from their families by offloading them but also as social support. They expressed that they could discuss their situation and get support from their families to maintain their ability to work: - My family is conscious about my problem. They also have the ability to see when the pain affects me. Of course they are helping me and are adjusting to my situation (VIII).

Support from authorities and health care. The authorities (Social insurance office and the Swedish public employment service) were perceived as having a considerable influence on, and responsibility for, the informants' future: - At the Social insurance office they never thought that I could continue to work and neither did I. And now I feel like this. It is very positive (IV). The informants perceived an information asymmetry between themselves, the authorities, and the health care services. The informants expressed that the authorities and the health care professionals needed to share their stock of knowledge with them. This helped the informants know what to expect and helped them to understand which types of work they would be able to do. It was perceived as important for the informants to quickly receive adequate health care and support from authorities in order to maintain their ability to work.

\subsection{Use of effective medication}

The informants perceived medication to be essential for them in order to be able to work. Medication was perceived to stabilize their disease, reduce pain and stiffness. When pain was growing stronger the informants used pain medication and cortisone to maintain their ability to work: - Constant pain makes it hard to sit and work ... I cool my joints with ice bags when the pain grows too strong and then I use pain medication (VII). 
- On Thursday evenings I wonder if I am able to work on Friday. Then I take the medication I have every evening and when I wake up next morning I am fit to work again ...sometimes I have thought that the medication is not that necessary but I feel really good when I have used it $(I V)$.

\section{Discussion}

The aim of this study was to explore how men with arthritis perceive their ability to maintain working. Six themes emerged from the data: desire to work; adjusted activity pattern; awareness of own capabilities; good work conditions; environmental support; and use of good medication. The results provided rich data for discussion from both theoretical and empirical perspectives.

The informants had a strong desire to work and work was highly valued. The results confirm the findings of previous research (14), which showed that a volition to work, a meaningful work for the individual but also being meaningful in a socio-cultural context were important aspects for individuals with arthritis in maintaining their ability to work. The result in the present study showed that the informants had a desire to be as everyone else. Financial requirements were expressed as a driving force to maintain working and the informants carried out their work despite pain and the risk of having setbacks. This was consistent with previous research $(14,24)$, which showed that men prioritised paid work over their own health in order to maintain their ability to work. The result of the present study also supports that the culture shapes which activities individuals prefer to engage in and what is meaningful for the individual but also meaningful in their socio-cultural context (27). This suggests that ability to work could be maintained in cultures that expect men to engage in work. Men with arthritis adjusted their activity pattern and prioritized work over household activities and leisure activities. This confirms previous findings (4) that a reduction of activities could be carried out in order to maintain ability to work and individuals with 
arthritis need to re-organise their life situation to maintain ability to work $(15,16)$. The results of the present study also support that a disruption in performance capacity required adjustments to the individuals' activity pattern (27). Activities could be changed or eliminated but also other ways of doing things could be discovered or learned in order to maintain ability to work.

The awareness of one's own capabilities evolved over time with the disease but the men with arthritis also learned to live with their reduced capabilities and adjusted their movement patterns to maintain their ability to work. This confirms previous research (4) that individuals with arthritis need to re-evaluate themselves and their capabilities. According to previous findings (16), individuals with arthritis need to challenge their disease in order to maintain their ability to work. The findings showed that in order to use one's capacity effectively the individual needs to be aware of their capabilities but also that those individuals who engage in work generate further experiences of their capabilities.

Previous research $(4,31)$ showed that flexible work conditions were of importance for individuals with arthritis in order to maintain their ability to work, which this study also confirms. Habituation has a significant impact on ability to work and routines give the individual a reference pattern of the amount of time necessary to conduct their work (27). This is in line with our finding showing that a predictable work day was important for maintaining work.

Furthermore, the individuals with arthritis, who had physically demanding work maintained ability to work when they had flexible work conditions, which is contrary to previous research (19) that showed that individuals with arthritis working with physically demanding work were more likely to fail to maintain their ability to work. Furthermore Gignac et al (32) found that working hours were reduced to maintain ability to work among individuals with arthritis, which was not replicated in the present study. A possible explanation for these 
differences might be gender differences. Even though there is no consensus if arthritis has a different impact on ability to work in women and men, there is research (17) showing that men continue to work to a greater extent than women. The present study had a focus on men while the two studies referred to above $(19,32)$ included both women and men, which might explain these inconsistencies.

Our result showed that the physical work environment just needed standard ergonomic adjustments as a natural part of the culture at the workplace. This confirms previous research (17), which showed that less than 40 per cent of the individuals with arthritis needed one or more adaptations of the physical work environment or technical devices. Finally, objects (here technical devices) are reflecting the personality of the individual and if the objects do not reflect the individuals' personality the individual chooses not to use them (27). Our result also indicates the need for supportive colleagues but rather highlights the size of the company than a supportive employer. This confirms previous research $(4,33)$, which showed that the social environment supports individuals with arthritis in maintaining their ability to work. An inconsistency in these findings was that the informants in our study did not show that support from the employer was important for maintaining work. A possible explanation is that it might be more likely in a larger company for the employer to be supportive and adjust the employees' work tasks or work conditions.

\subsection{Practical implications}

The results of this study point out some considerations, which could be used by the multi professional team supporting men with arthritis to maintain their ability to work. The findings of the present study suggested that health care professionals could help men with arthritis to find less physically demanding leisure activities in which to engage but also to find a balance between recreation and work. Health care professionals could teach men with arthritis strategies to cope with physically demanding activities. Coping strategies could be to split up 
activities up, to change pace in activities or to alternate between heavier and lighter work tasks in accordance with how they feel each day. Health care professionals could study movement patterns in men with arthritis and help them adapt to a gentler and slower movement pattern. They could examine the work place and make sure that there are standard ergonomic adjustments. This study highlights the impacts of the cultural and social environment and thus solutions must be culturally and socially accepted.

\subsection{Limitations of the study}

There are some methodological concerns to draw attention to in this study. Data in this study is only from interviews. Triangulation, to strengthen the validity and to gain in-depth qualitative data was not conducted (30). Interviews might thus be a limited source of data. The EPP method requires text-based data from the informants' own perspective (29), and thus it could be argued that triangulation was not necessary in this study. McCracken (34) argues that in qualitative and explorative studies a small sample of about ten informants is enough to obtain adequate and rich data. Depoy and Gitlin (30) maintain that the degree of saturation is reached when the collected data does not give any new information about the phenomenon, and no new information of the phenomenon emerged in the two last interviews. Nevertheless, if the data collection had continued new information of the phenomenon might have emerged. The small number of informants who participated in this study might therefore have affected the validity of the result if the degree of saturation was not reached. However, this study should be considered as a pilot study to provide a basic understanding (30) of how men with arthritis maintain their ability to work which could be essential for interventions for men with arthritis.

\section{Conclusion}

This study has provided an understanding of how men with arthritis maintain their ability to work. The findings showed that men with arthritis perceived a desire to work, adjusted their 
activity pattern, were aware of their own capabilities, had good work conditions, had environmental support and used good medication for maintaining their ability to work. In conclusion, to treat the symptoms of arthritis, in the more traditional way that for example hand dysfunction and pain are treated, may prevent sick-leave but as found in the present study the ability to work is complex and new strategies to support ability to work need to be developed in the occupational aspects of rheumatology care.

\section{Acknowledgements}

We are grateful to the informants for their participation in this study and are thankful to the executives and the occupational therapists at the rheumatology units for their support and help during the data collection.

\section{References}

1. Young A, Dixey J, Kulinskaya E, Cox N, Davies P, Devlin J, et al. Which patients stop working because of rheumatoid arthritis? Results of five years' follow up in 732 patients from the early RA study (ERAS). Ann Rheumtol. 2002;61(4):335-40.

2. Allaire SH. Update on work disability in rheumatic diseases. Current opinion in rheumatology. 2001;13(2):93-8.

3. Mau W, Bornmann M, Weber H, Weidemann HF, Hecker H, Raspe HH. Prediction of permanent work disability in a follow-up study of early rheumatoid arthritis: results of a tree structured analysis using RECPAM. Br J Rheumatol. 1996;35(7):652-9.

4. Wolfe F, Hawley DJ. The longterm outcomes of rheumatoid arthritis: Work disability: a prospective 18 year study of 823 patients. J Rheumatol. 1998;25(11):2108-17.

5. Mau W, Listing J, Huscher D, Zeidler H, Zink A. Employment across chronic inflammatory rheumatic diseases and comparison with the general population. J Rheumatol. 2005;32(4):721-8. 
6. Oliver S. Best practice in the treatment of patients with rheumatoid arthritis. Nurs Stand. 2007;21(42):47-56.

7. Law M, Steinwender S, Leclair L. Occupation, health and well-being. Can J Occup Ther. $1998 ; 65(2): 81-91$

8. Kielhofner G, Braveman B, Baron K, Fisher G, Hammel J, Littleton M. The model of human occupation: understanding the worker who is injured or disabled. Work. $1999 ; 12(1): 37-45$.

9. Simard JF, Arkema EV, Sundström A, Geborek P, Saxne T, Baecklund E, et al. Ten years with biologics: to whom do data on effectiveness and safety apply? Rheumatology. 2011;50(1):204-13.

10. Curtis JR, Singh JA. Use of biologics in rheumatoid arthritis: current and emerging paradigms of care. Clin Ther. 2011;33(6):679-707.

11. Linden C, Bjorklund A. Living with rheumatoid arthritis and experiencing everyday life with TNF-alpha blockers. Scand J Occup Ther. 2010;17(4):326-34.

12. Neovius M, Simard JF, Klareskog L, Askling J. Sick leave and disability pension before and after initiation of antirheumatic therapies in clinical practice. Ann Rheum Dis. 2011;70(8):1407-14.

13. Dubouloz CJ, Laporte D, Hall M, Ashe B, Smith CD. Transformation of meaning perspectives in clients with rheumatoid arthritis. The American journal of occupational therapy : official publication of the American Occupational Therapy Association. 2004;58(4):398-407.

14. Stamm TA, Machold KP, Smolen J, Prodinger B. Life stories of people with rheumatoid arthritis who retired early: how gender and other contextual factors shaped their everyday activities, including paid work. Musculoskel Care. 2010;8(2):78-86. 
15. Stamm T, Lovelock L, Stew G, Nell V, Smolen J, Machold K, et al. I have a disease but I am not ill: a narrative study of occupational balance in people with rheumatoid arthritis.

Occup Ther J Rehab: Occup, Participat Health. 2009;29(1):32-9.

16. Stamm T, Lovelock L, Stew G, Nell V, Smolen J, Jonsson H, et al. I have mastered the challenge of living with a chronic disease: life stories of people with rheumatoid arthritis. Qual Health Res. 2008;18(5):658-69.

17. Kaptein SA, Gignac MA, Badley EM. Differences in the workforce experiences of women and men with arthritis disability: a population health perspective. Arthritis and rheumatism. 2009;61(5):605-13.

18. Barrett EM, Scott DG, Wiles NJ, Symmons DP. The impact of rheumatoid arthritis on employment status in the early years of disease: a UK community-based study.

Rheumatology. 2000;39(12):1403-9.

19. de Croon EM, Sluiter JK, Nijssen TF, Dijkmans BA, Lankhorst GJ, Frings-Dresen MH. Predictive factors of work disability in rheumatoid arthritis: a systematic literature review. Ann Rheum Dis. 2004;63(11):1362-7.

20. Björk M, Thyberg I, Rikner K, Balogh I, Gerdle B. Sick leave before and after diagnosis of rheumatoid arthritis in relation to referents: a report from the Swedish TIRA project. J Rheumatol. 2009;36(6):1170-9.

21. Bjork M, Thyberg I, Haglund L, Skogh T. Hand function in women and men with early rheumatoid arthritis. A prospective study over three years (the Swedish TIRA project). Scand J Rheumatol. 2006;35(1):15-9.

22. Sandqvist G, Scheja A, Hesselstrand R. Pain, fatigue and hand function closely correlated to work ability and employment status in systemic sclerosis. Rheumatology. 2010;49(9):1739-46. 
23. Odegård S, Finset A, Kvien TK, Mowinckel P, Uhlig T. Work disability in rheumatoid arthritis is predicted by physical and psychological health status: a 7-year study from the Oslo RA register. Scand J Rheumatol. 2005 34(6):441-7.

24. Gibbs L. Identifying work as a barrier to men's access to chronic illness (arthritis) selfmanagement programs. Intern J Men's Health. 2007;6(2):143-55.

25. Affleck G, Tennen H, Keefe FJ, Lefebvre JC, Kashikar-Zuck S, Wright K, et al. Everyday life with osteoarthritis or rheumatoid arthritis: independent effects of disease and gender on daily pain, mood, and coping. Pain. 1999;83(3):601-9.

26. Thyberg I, Hass UA, Nordenskiöld U, Skogh T. Survey of the use and effect of assistive devices in patients with early rheumatoid arthritis: a two-year follow up of women and men. Arthritis Care Res. 2004;51(3):413-21.

27. Kielhofner G. Model of human occupation: Theory's and application. Baltimore: Lippincott Williams \& Wilkins; 2008.

28. Hvalsoøe B, Josephsson S. Characteristics of meaningful occupations from the perspective of mentally ill people. Scand J Occup Ther. 2003;10(2):61-71.

29. Karlsson G. Psychological qualitative research from a phenomenological perspective. Stockholm Almqvist \& Wiksell International; 1993.

30. Depoy E, Gitlin LN. Introduction to Research: Understanding and Applying Multiple Strategies. St Louis: C.V. Mosby; 2005.

31. Yelin E. Work disability in rheumatic diseases. Current opinion in rheumatology. 2007;19(2):91-6.

32. Gignac MA, Cao X, Lacaille D, Anis AH, Badley EM. Arthritis-related work transitions: a prospective analysis of reported productivity losses, work changes, and leaving the labor force. Arthritis and rheumatism. 2008;59(12):1805-13. 
33. Varekamp I, Haafkens JA, Detaille SI, Tak PP, van Dijk FJ. Preventing work disability among employees with rheumatoid arthritis: what medical professionals can learn from the patients' perspective. J Arthrit Rheumatol. 2005;53(6):965-72.

34. McCracken, G. The long interview. Newbury Park CA: Sage; 1988. 
Table 1. Demographic data.

\begin{tabular}{lllllll}
\hline Informant & Age & Profession & $\begin{array}{l}\text { Present service } \\
\text { grade }\end{array}$ & Marital status & Type of arthritis & $\begin{array}{l}\text { Symptoms } \\
\text { since }\end{array}$ \\
\hline I & 46 & Blue collar & $75 \%$ & Married & Psoriasis arthritis & $<10$ years \\
II & 53 & Blue collar & $100 \%$ & Married & Rheumatoid arthritis & $<10$ years \\
III & 57 & White collar & $50 \%$ & Single & Rheumatoid arthritis & $<10$ years \\
IV & 62 & Blue collar & $100 \%$ & Married & Rheumatoid arthritis & $<5$ years \\
V & 53 & Blue collar & $100 \%$ & Married & Rheumatoid arthritis & $>5$ years \\
VI & 41 & Blue collar & $100 \%$ & Single & Rheumatoid arthritis & $<10$ years \\
VII & 31 & White collar & $100 \%$ & Girlfriend & Psoriasis arthritis & $<10$ years \\
VIII & 44 & White collar & $100 \%$ & Married & Psoriasis arthritis & $>5$ years \\
IX & 45 & Blue collar & $100 \%$ & Married & Rheumatoid arthritis & $<10$ years \\
& & & & & Ankylosing spondylitis & \\
& & & & Psoriasis arthritis &
\end{tabular}


Table 2. Explanations of stage one to five in the data analysis and examples of how data were analyzed accordingly.

\begin{tabular}{|c|c|c|c|}
\hline $\begin{array}{l}\text { Stage 1: Transcripts were } \\
\text { repeatedly read to get a } \\
\text { good grasp of the } \\
\text { content. Stage 2: } \\
\text { Transcripts were then } \\
\text { searched line by line to } \\
\text { organise them into } \\
\text { meaning units }\end{array}$ & $\begin{array}{l}\text { Stage 3: Meaning unit was } \\
\text { transformed into the } \\
\text { researcher's language. } \\
\text { Interpretation was moved } \\
\text { from embedded facts } \\
\text { relating to the } \\
\text { phenomenon into implicit } \\
\text { and explicit meaning }\end{array}$ & $\begin{array}{l}\text { Stage 4: Meaning units } \\
\text { were omitted and shifted } \\
\text { to synthesize summary } \\
\text { formats (situated } \\
\text { structures) where themes } \\
\text { and sub-themes emerged. } \\
\text { Themes and sub-themes } \\
\text { were controlled towards } \\
\text { the transcripts. }\end{array}$ & $\begin{array}{l}\text { Stage 5: A general } \\
\text { structure was created } \\
\text { by comparing all } \\
\text { situated structures. } \\
\text { These were presented } \\
\text { in running text with } \\
\text { meaning units as } \\
\text { quotations. }\end{array}$ \\
\hline & & $\begin{array}{l}\text { Desire to be as everyone } \\
\text { else. }\end{array}$ & \\
\hline
\end{tabular}

everyone else ... I would

like to live as usual ...I

used to bite the bullet to

be able to continue to

work

I am not as reckless any

longer when I do things...

I think my pattern of

movement is calmer than

before

You always need to think

about what you are doing

and plan the next step.

How to lift things or when

to call for help

It is a big employer. If I do

not have the abilities to

execute my work then

they can test me at

another workplace. A

workplace which is more

suitable for me

everyone else. There is a

desire to continue to live

like before arthritis.

The pattern of movement

is calmer nowadays than

before to avoid reckless

movements.

Planning the day is

Predictable workday

Good work conditions

necessary to execute

work.

Adjusted movement

pattern

Awareness of own

capabilities

The informant works in a

larger company. This

company has the

resources to try him on

another workplace if it

would be necessary.
The size of the company.

Environmental support 
Table 3. Schematic overview of themes and sub-themes

\begin{tabular}{|c|c|}
\hline Theme & Sub-theme \\
\hline \multirow[t]{2}{*}{ Desire to work } & Meaningful work \\
\hline & Desire to be as everyone else \\
\hline \multirow[t]{3}{*}{ Adjusted activity pattern } & Adjusted leisure activities \\
\hline & More recreation \\
\hline & Adjusted household activities \\
\hline \multirow[t]{3}{*}{ Awareness of own capabilities } & Learn to live with reduced capabilities \\
\hline & Adjusted work pace \\
\hline & Adjusted movement pattern \\
\hline \multirow[t]{2}{*}{ Good work conditions } & Flexible work conditions \\
\hline & Predictable workday \\
\hline \multirow[t]{5}{*}{ Environmental support } & Objects and spaces in the workplace \\
\hline & The size of the company \\
\hline & Support from colleagues \\
\hline & Support from families \\
\hline & Support from authorities and health care \\
\hline Use of effective medication & \\
\hline
\end{tabular}

